\title{
THE HON ROBERT TICKNER,M.P. MINISTER FOR ABORIGINAL AND TORRES STRAIT ISLANDER AFFAIRS
}

I am delighted to have the opportunity of congratulating The Aboriginal child at School Journal on its twenty-first year of publication.

The entitlement to equitable education is an important, and indeed instrumental right, which is particularly critical to addressing the social, economic and cultural disadvantages faced by Aboriginal and Torres Strait Islander peoples.

The Aboriginal Child at School Journal plays a critical role in this process by keeping teachers working in Aboriginal and Torres Strait Islander education in communication not only with each other, but in touch with general developments in the field of indigenous education.

Such a forum is particularly important to assist in improving rates of Aboriginal and Torres Strait Islander peoples' participation in education as well as educational outcomes.

As a Journal which has such a good track record, I look forward to its continued publication and would like to congratulate all those talented individuals who have been involved in its production, both presently, and in the past, for their good work, and wish the Journal every success for the future.

With kind regards

Yours sincerely

Robert Tickner.

16th June 1994

$-5 \cdot$ 